\title{
PENGARUH MODEL THINK PAIR SHARE DAN MEDIA CROSSWORD PUZZLE UNTUK MENINGKATKAN MINAT BELAJAR MATEMATIKA SISWA SEKOLAH DASAR DI NGEMBALREJO BAE KUDUS
}

\author{
Taufiqur Rohman ${ }^{1}$, Sri Surachmi W' ${ }^{2}$,an Murtono ${ }^{3}$ \\ 1,2,3 Universitas Muria Kudus, Kudus, Indonesia \\ ${ }^{1}$ taufiq.rr94@gmail.com, ${ }^{2}$ amirachmi.w@gmail.com, ${ }^{3}$ murtono@umk.ac.id
}

\begin{abstract}
ABSTRAK
Penelitian ini bertujuan untuk: (1) Menganalisis pengaruh model Think Pair Share terhadap minat belajar siswa dalam Matematika di SD 2 Ngembalrejo Bae Kudus (2) Menganalisis pengaruh media crosswors puzzle terhadap minat belajar siswa dalam Matematika di SD 4 Ngembalrejo Bae Kudus Hasil (3) Menganalisis Pengaruh model Think Pair Share dan media crosswors puzzle terhadap minat belajar siswa dalam Matematika di SD 5 Ngembalrejo Bae Kudus. Metode yang digunakan adalah metode kuantitatif analisis data dengan statistik. Dalam penelitian ini, penulis melakukan studi lapangan di sekolah dasar di desa Ngembalrejo. Populasi dalam penelitian ini terdiri dari siswa Kelas 5 di empat SD, yaitu SD 2 Ngembalrejo, SD 4 Ngembalrejo, SD 5 Ngembalrejo, dan SD 3 Ngembalrejo sebagai kelas kontrol dengan menggunakan teknik simple random sampling. Dalam analisis ini, penulis menggunakan analisis statistik, yaitu regresi dan korelasi sederhana. Hasil penelitian menunjukkan bahwa 1) Model Think Pair Share pada minat belajar matematika siswa di SD 2 Ngembalrejo Bae Kudus dalam kategori baik, adalah 41 dalam rentang interval 41-49. 2) Media Crossord Puzzle pada minat belajar matematika siswa di SD 4 Ngembalrejo Bae Kudus dalam kategori sangat baik, yairu 41 dalam rentang interval 41-49. 3) ) Model Think Pair Share dan Media Crossord Puzzle pada minat belajar matematika siswa di SD 5 Ngembalrejo Bae Kudus dalam kategori baik, adalah 52 dalam rentang interval $52-62$ 4) Terdapat pengaruh signifikan dari model Think Pair Share dan media crosswors puzzle untuk meningkatkan minat belajar matematika siswa Sekolah Dasar di Ngambalrejo Bae Kudus, dengan persamaan regresi $\hat{Y} 1=49.630+0.381 \mathrm{X} 1, \hat{\mathrm{Y}} 2=50.985+0.342 \mathrm{X} 2, \hat{\mathrm{Y}} 3=51.226+0.683 \mathrm{X} 3$. Model Think Pair Share memiliki jumlah positif dan signifikan menjadi 0.336 yang termasuk dalam kategori rendah dan dapat berkontribusi kepada siswa dalam ,meningkatkan minat belajar matematika siswa sebesar $11.27 \%$ di SD 2 Ngembalrejo. Media crosswors puzzle memiliki jumlah positif dan signifikan menjadi 0.345 yang termasuk dalam kategori rendah dan dapat berkontribusi kepada siswa dalam ,meningkatkan minat belajar matematika siswa sebesar 11.875\% di SD 4 Ngembalrejo. Model Think Pair Share dan Media crosswors puzzle memiliki jumlah positif dan signifikan menjadi 0.356 yang termasuk dalam kategori rendah dan dapat berkontribusi kepada siswa dalam, meningkatkan minat belajar matematika siswa sebesar $12.647 \%$ di SD 5 Ngembalrejo.
\end{abstract}

Kata Kunci: model think pair share, media teka teki silang, minat belajar matematika

\section{THE INFLUENCE OF THINK PAIR SHARE MODEL AND CROSSWORD PUZZLE TO INCREASE ELEMENTARY SCHOOL STUDENTS' MATHEMATICAL LEARNING INTERESTS IN NGEMBALREJO BAE KUDUS}

\begin{abstract}
This study aimed to: (1) analyze the effect of the Think Pair Share model on students' interest in learning in Mathematics at SD 2 Ngembalrejo Bae Kudus, (2) analyze the effect of crossword puzzle media on students' interest in learning mathematics at SD 4 Ngembalrejo Bae Kudus Results. (3) analyze the influence of Think Pair Share model and the crossword puzzle media on students' interest in learning mathematics at SD 5 Ngembalrejo Bae Kudus. The method used in this study was a quantitative method of data analysis with statistics. In this study, the researchers conducted a field study at one of the elementary schools in Desa Ngembalrejo. The population in this study consisted of Grade 5 students at four elementary schools, namely SD 2 Ngembalrejo, SD 4 Ngembalrejo, SD 5 Ngembalrejo, and SD 3 Ngembalrejo chosen as the control class through a simple random sampling technique. In this study, the researchers used statistical analysis, namely simple regression and correlation. The results showed that 1) the Think Pair Share model increased students' interest in learning mathematics at SD 2 Ngembalrejo Bae Kudus since it was in Good category with a score of 41 in the 41-49 interval range. 2) Crossword Puzzle media also increased students' interest in learning mathematics at SD 4 Ngembalrejo Bae Kudus in the Very Good category with a score of 41 in the $41-49$ interval range. 3) Think Pair Share and Media Crossword Puzzle models increased students' interest in learning mathematics at SD 5 Ngembalrejo Bae Kudus in the Good category, with a score of 52 in the interval range of 52-62. 4) There was a significant effect of the Think Pair Share model and crosswords puzzle media on students' interest in learning mathematics at elementary school in Ngambalrejo Bae Kudus, with the regression equation of Y1 = $49.630+$ $0.381 X_{1}, Y 2=50.985+0.342 X_{2}, Y 3=51.226+0.683 X_{3}$. Thus, the Think Pair Share model had a positive and significant score of 0.336 which was included in Low category and contributed to increasing students' interest in learning mathematics by $11.27 \%$ at SD 2 Ngembalrejo. Then, the crossword puzzle media had a positive and significant score of 0.345 which was included in Low category and contributed to increasing students' interest in learning mathematics by $11.875 \%$ at SD 4 Ngembalrejo. To conclude. Think Pair Share and Media crosswords puzzle models had a positive and significant score of 0.356 which was included in the low category and contributed to increasing students' interest in learning mathematics by $12.647 \%$ at SD 5 Ngembalrejo.
\end{abstract}

Keywords: think pair share model, media crossword puzzle, mathematics learning interest

\begin{tabular}{|c|c|c|}
\hline Submitted & Accepted & Published \\
\hline 09 Mei 2021 & 05 September 2021 & 18 November 2021 \\
\hline
\end{tabular}

\begin{tabular}{|l|c|c|}
\hline Citation & $:$ & $\begin{array}{r}\text { Rohman, T., W Surachmi, S., \& Murtono, M. (2021). Pengaruh Model Think Pair Share Dan Media Crossword Puzzle } \\
\text { Untuk Meningkatkan Minat Belajar Matematika Siswa Sekolah Dasar Di Ngembalrejo Bae Kudus. Jurnal PAJAR } \\
\text { (Pendidikan dan Pengajaran), 5(6), 1544-1549. DOI : http://dx.doi.org/10.33578/pjr.v5i6.8341. }\end{array}$ \\
\hline
\end{tabular}




\section{PENDAHULUAN}

Pembelajaran yang berkualitas dapat dilihat dari keberhasilannya dalam proses kegiatan belajar mengajar. Keberhasilan ini sangat ditentukan oleh bagaimana guru menerapkan model pembelajaran tersebut. Model pembelajaran merupakan kerangka kerja konseptual yang menggambarkan prosedur sistematis penyelenggaraan pengalaman belajar untuk mencapai tujuan pembelajaran tertentu dan berfungsi sebagai pedoman bagi desainer pembelajaran dan guru dalam merencanakan kegiatan belajar mengajar agar tujuan pembelajaran tercapai. Oleh karena itu pemilihan model pembelajaran yang tepat akan mendukung proses pembelajaran yang berjalan efektif dan efisien, serta dapat mencapai tujuan pembelajaran dengan tepat. Hal tersebut, tujuan pembelajaran yang ingin dicapai adalah tercapainya hasil belajar siswa yang optimal. Seperti yang kita ketahui dan alami sendiri, pembelajaran Matematika pada umumnya didominasi oleh pengenalan rumusrumus Matematika, lambang-lambang dan lambang-lambang tulisan Matematika, serta penanaman konsep-konsep Matematika hanya berdasarkan rumus-rumus saja tanpa ada penjelasan yang nyata.

Pembelajaran kooperatif merupakan pembelajaran dimana para siswa bekerja dalam kelompok-kelompok kecil untuk asaling membantu satu sama lainnya dalam mempelajari materi. Cara belajar kooperatif, lebih seringnya menggantikan pengaturan tempat duduk yang individual, cara belajar individual, dan dorongan yang individual. Jika diatur dengan baik, siswasiswa dalam kelompok kooperatif akan belajar satu sama lain untuk memastikan bahwa tiap orang dalam kelompok telah menguasai konsep-konsep yang telah dipikirkan. Setiap anggota kelompok memiliki tanggung jawab yang sama untuk keberhasilan kelompoknya. Model Think Pair Share ini merupakan salah satu model pembelajaran kooperatif, dimana siswa bertanggung jawab atas pembelajarannya dan guru hanya sebagai fasilitator. Menurut Agus Suprijono, pembelajaran kooperatif merupakan konsep yang lebih luas yang mencakup semua jenis kerja kelompok termasuk bentuk yang lebih dipimpin oleh guru atau diarahkan oleh guru (Agus Suprijono, 2014).

\section{KAJIAN TEORETIS \\ Model Think Pair Share}

Model pembelajaran Think pair Share ini merupakan salah satu model pembelajaran kooperatif, dimana peserta didik bertanggungjawab atas belajar mereka dan Guru hanya sebagai fasilitator. Menurut Agus Suprijono, Pembelajaran kooperatif adalah konsep yang lebih luas meliputi semua jenis kerja kelompok termasuk bentuk-bentk yang lebih dipimpin oleh Guru atau diarahkan oleh Guru (Suprijono, 2013). Seperti namanya " Thingking", pembelajaran ini diawali dengan Guru mengajukan pertanyaan yang terkait dengan pelajaran untuk dipikirkan oleh siswa. Guru memberi kesempatan kepada mereka memikirkan jawabannya. Selanjutnya," Pairing “ pada tahap ini Guru meminta agar siswa berpasang-pasangan untuk berdiskusi. Hasil diskusi selanjutnya tiap-tiap pasangan hasilnya dibicarakan dengan pasangan seluruh kelas, dan tahap inilah yang dikenal dengan "Sharing" (Suprijono, 2013).

\section{Media Crossword Puzzle}

Crossword Puzzle (teka-teki silang) merupakan salah satu metode pembelajaran yang dikembangkan dari strategi active learning. Melvin menjelaskan pengertian model Crossword Puzzle dengan suatu permainan dimana kita harus mengisi ruang-ruang kosong (berbentuk kotak putih) dengan huruf-huruf yang membentuk sebuah kata berdasarkan petunjuk yang diberikan. Petunjuk bisa dibagi ke dalam kategori mendatar dan menurun tergantung posisi kata-kata yang harus diisi (Melvin L. Silberman, 2010). Penggunaan media dalam kegiatan pembelajaran sangat perlu karena untuk mempermudah proses pembelajaran sehingga dapat mencapai hasil yang optimal. Tanpa metode yang jelas, proses pembelajaran tidak akan terarah sehingga tujuan pembelajaran yang telah ditetapkan sulit tercapai secara optimal, 
dengan kata lain pembelajaran sangat berguna baik bagi guru maupun siswa.

\section{Minat Belajar Siswa}

Minat adalah kecenderungan siswa yang relatif menetap kepada diri seseorang yang biasanya disertai dengan perasaan senang. Menurut Berhard "minat" timbul atau muncul tidak secara tiba-tiba, melainkan timbul akibat dari partisipasi, pengalaman, kebiasaan pada waktu belajar atau bekerja. Minat juga dapat menjadi penyebab kegiatan dan penyebab partisipasi dalam kegiatan. Sedangkan pengertian belajar adalah suatu kegiatan yang menimbulkan suatu perubahan tingkah laku yang relatif tetap dan perubahan itu dilakukan lewat kegiatan, atau usaha yang disengaja. Jadi, yang dimaksud dari minat belajar adalah aspek psikologi seseorang yang menempakkan diri dalam beberapa gejara, seperti: gairah, keinginan, perasaan suka untuk melakukan proses berubahan tingkah laku melalui berbagai kegiatan yang meliputi mencari pengetahuan dan pengalaman, dengan kata lain, minat belajar itu adalah perhatian, rasa suka keterkaitan seseorang (peserta didik) terhadap belajar yang ditunjukkan melalui keantusiasan, partisipasi dalam belajar (Muhammad Fathurrohman dan Sulistyorini, 2012).

\section{METODE PENELITIAN}

Penelitan ini merupakan jenis penelitian kuantitatif analisis data dengan statistik (Sugiyono, 2013). Dalam penelitian ini, penulis melakukan studi lapangan di sekolah dasar di Ngembalrejo. Populasi dalam penelitian ini terdiri dari siswa Kelas 5 di empat SD, yaitu SD 2 Ngembalrejo, SD 4 Ngembalrejo, SD 5 Ngembalrejo, dan SD 3 Ngembalrejo sebagai kelas kontrol dengan menggunakan teknik simple random sampling. Dalam analisis ini, penulis menggunakan analisis statistik, yaitu regresi dan korelasi sederhana.
Metode analisis data dalam penelitian ini menggunakan beberapa uji hipotesis, diantaranya yaitu hipotesis deskriptif (uji t) dan hipotesis asosiatif (Freg, uji t). Analisis deskriptif digunakan untuk menganalisis data: 1) pengaruh model think pair share terhadap minat belajar, 2) pengaruh media crossword puzzle terhadap minat belajar, serta 3 ) pengaruh model think pair share dan media crossword puzzle terhadap minat belajar. Uji hipotesis deskriptif dan hipotesis asosiatif digunakan untuk pembuktian kebenaran hipotesis yang peneliti ajukan.

Angket kuisioner yang akan dibagikan kepada siswa dianalisis menggunakan perhitungan validitas isi dengan formula aiken sebagai berikut:

$$
v=\frac{\sum s}{\mathrm{n}(\mathrm{c}-1)}
$$

Keterangan:

S $\quad: \mathrm{r}$ - Io $\Rightarrow \mathrm{s}$ : selisih antara skor yang ditetapkan rater (r) dan skor terendah

$\mathrm{V} \quad$ : Indeks validitas butir

n : Banyaknya rater

c : Angka penilaian validitas yang tertinggi

Io : Angka penilaian validitas yang terendah

$\mathrm{r} \quad$ : Angka yang diberikan oleh seseorang penilai rater

Pada validitas angket kuisioner dilakukan oleh 3 ahli yang berasal dari akademisi, dimana dengan mengambil rata-rata skor dari validator. Masing-masing Validator akan memberikan penilaian terhadap angket kuisioner. Data yang diperoleh dari validator kemudian dianalisis berdasarkan rata-rata skor dan masing-masing angket kuisioner yang dihitung dengan cara membagi antara jumlah skor masing- masing perangkat dibagi dengan banyaknya aspek penilaian dari rater. Angket kuisioner akan dikatakan valid apabila skor rata-rata dalam kategori "tinggi" sebagaimana pada tabel kriteria validitas perangkat pembelajaran. 
Tabel 1. Validitas Angket Kuisioner

\begin{tabular}{cc}
\hline Interval & Kriteria \\
\hline $0.80<\mathrm{V} \leq 1.00$ & Sangat tinggi \\
$0.60<\mathrm{V} \leq 0.80$ & Tinggi \\
$0.40<\mathrm{V} \leq 0.60$ & Cukup \\
$0.20<\mathrm{V} \leq 0.40$ & Rendah \\
$0.00<\mathrm{V} \leq 0.20$ & Sangat rendah \\
\hline
\end{tabular}

Minat belajar matematika siswa dihitung dengan menggunakan angket yang kemudian dikelompokkkan dengan persentase respon siswa. Respon siswa dinyatakan bergerak kearah positif apabila menunjukkan posisi minimal "tinggi".

Uji hipotesis deskriptif dan hipotesis asosiatif digunakan untuk pembuktian kebenaran hipotesis yang peneliti ajukan, untuk mengetahui apakah minat belajar matematika siswa dengan model think pair share dan media crossword puzzle di Ngembalrejo bae Kudus lebih baik daripada minat belajar matematika siswa dengan pembelajaran konvensional (model ceramah).

\section{HASIL DAN PEMBAHASAN}

Berdasarkan analisis yang telah peneliti lakukan, maka pembahasannya adalah sebagai berikut:

Model Think Pair Share tidak sama dengan sekedar belajar dalam kelompok. Pelaksanaan prosedur model pembelajaran kooperatif tipe Think Pair Share dengan benar akan memungkinkan guru mengelola kelas lebih efektif. Selain itu juga siswa akan menjadi lebih aktif dalam belajar karena akan selalu berinteraksi dengan temanteman yang lain dalam mengerjakan tugas. Penerapan model Think Pair Share di SD 2 Ngembalrejo Ngembalrejo Bae Kudus termasuk dalam kategori baik, yaitu sebesar 41 pada rentang interval 41-49.

Media Crossword Puzzle merupakan permainan yang terdiri dari potongan gambargambar, kotak-kotak, huruf-huruf atau angkaangka yang disusun seperti dalam sebuah permainan yang akhirnya membentuk sebuah pola tertentu sehingga membuat peserta didik menjadi termotivasi untuk menyelesaikannya secara tepat dan cepat. Diantara media-media siswa yang tercipta, Crossword Puzzle merupakan metode pembelajaran aktif yang melibatkan semua peserta didik untuk berfikir dengan menggunakan tekateki. Penerapan media crossword puzzle SD 4 Ngembalrejo Bae Kudus termasuk dalam kategori baik, yaitu sebesar 41 pada rentang interval 41 49.

Model Think Pair Share dan Media Crossword Puzzle tidak sama dengan sekedar belajar dalam kelompok. Pelaksanaan prosedur model pembelajaran kooperatif tipe Think Pair Share dan Media Crossword Puzzle dengan benar akan memungkinkan guru mengelola kelas lebih efektif. Selain itu juga siswa akan menjadi lebih aktif dalam belajar karena akan selalu berinteraksi dengan teman-teman yang lain dalam mengerjakan tugas untuk berfikir dengan menggunakan tekateki. Penerapan media crossword puzzle SD 4 Ngembalrejo Bae Kudus termasuk dalam kategori baik, yaitu sebesar 52 pada rentang interval 52-62

Penerapan kelas kontrol di SD 3 Ngembalrejo Bae Kudus termasuk dalam kategori cukup, yaitu sebesar 37 pada rentang interval 3037. Minat Belajar adalah kecerdasan memahami orang lain dan berproses melalui interakti bersama mereka. Karakteristik yang menonjol dari minat ini adalah empati, pemahaman dan kesadaran akan tujuan dan maksud orang lain. Siswa dengan minat belajar yang berkembang baik akan sangat menikmati kegiatan kelompok dan collaborative learning. Mereka juga sangat suka dengan kegiatan yang mengharuskan mereka melakukan pengamatan gambar jenis-jenis pekerjaan, melakukan interaksi dengan guru, menetapkan aturan kelas, menentukan dan membagi tugas dan tanggung jawab dan mengikuti permainan yang melibatkan upaya menyesuaikan suatu konflik. Minat belajar siswa kelas 5 Sekolah Dasar di Ngembalrejo Bae Kudus dalam kategori tinggi, sebesar 55 pada rentang interval 54-62. Sebuah metode investigasi-kooperatif dari pembelajaran di kelas diperoleh dari premis bahwa baik dominan 
sosial maupun intelektual proses pembelajaran di sekolah melibatkan nilai-nilai yang didukungnya. Model Think Pair Share tidak dapat diimplementasikan dalam lingkungan pendidikan yang tidak mendukung dialog interpersonal di dalam kelas. Komunikasi dan interaksi kooperatif antara sesama teman sekelas akan mencapai hasil terbaik apabila dilakukan dalam kelompok kecil, di mana pertukaran diantara teman sekelas dan sikapsikap kooperatif bisa terus bertahan. Aspek social dari kelompok, pertukaran intelektualnya, dan maksud dari subjek yang berkaitan dengannya dapat bertindak sebagai sumber-sumber penting maksud tersebut bagi usaha para siswa untuk belajar. Jadi, dapat disimpulkan bahwa model think pair share dan media crossword puzzle berpengaruh cukup signifikan terdapat minat belajar siswa, dengan persamaan regresi $\hat{\mathrm{Y}} 1=$ $49.630+0.381 \mathrm{X} 1, \hat{\mathrm{Y}} 2=50.985+0.342 \mathrm{X} 2, \hat{\mathrm{Y}} 3=$ $51.226+0.683 \mathrm{X} 3, \hat{\mathrm{Y}} 4=49.096+0.169 \mathrm{X} 4$ artinya apabila model think pair share dan media crossword puzzle ditingkatkan maka minat belajar siswa akan meningkat. Pengaruh model think pair share ini memiliki hubungan yang positif dan cukup signifikan sebesar 0.336 yang termasuk dalam kategori rendah dan dapat memberikan kontribusi bagi peserta didik dalam meningkatkan minat belajar matematika di SD 2 Ngembalrejo sebesar $11.27 \%$. Pengaruh media crossword puzzle ini memiliki hubungan yang positif dan cukup signifikan sebesar 0.345 yang termasuk dalam kategori rendah dan dapat memberikan kontribusi bagi peserta didik dalam meningkatkan minat belajar matematika di SD 4 Ngembalrejo sebesar $11.875 \%$. Pengaruh model think pair share dan media crossword puzzle ini memiliki hubungan yang positif dan cukup signifikan sebesar 0.356 yang termasuk dalam kategori rendah dan dapat memberikan kontribusi bagi peserta didik dalam meningkatkan minat belajar matematika di SD 5 Ngembalrejo sebesar $12.647 \%$. Pengaruh kelas kontrol (model ceramah) ini memiliki hubungan yang positif dan cukup signifikan sebesar 0,093 yang termasuk dalam kategori sangat rendah dan dapat memberikan kontribusi bagi peserta didik dalam meningkatkan minat belajar matematika di SD 3 Ngembalrejo sebesar $0.9 \%$.

Tabel 1. Hasil Penelitian

\begin{tabular}{|c|c|c|c|c|c|c|c|}
\hline \multirow[b]{2}{*}{ Variabel } & \multirow[b]{2}{*}{ Interval } & \multirow{2}{*}{$\begin{array}{c}\text { Uji } \\
\text { Normalitas }\end{array}$} & \multirow{2}{*}{$\begin{array}{c}\text { Uji } \\
\text { Hipotesis } \\
\text { Deskriptif }\end{array}$} & \multicolumn{4}{|c|}{ Uji Hipotesis Asosiatif } \\
\hline & & & & Freg & $\begin{array}{l}\text { t (konstanta } \\
\text { regresi) }\end{array}$ & $\begin{array}{l}\mathrm{t}(\text { koefisien } \\
\text { regresi) }\end{array}$ & $\begin{array}{l}\mathrm{t} \text { (koefisien } \\
\text { korelasi) }\end{array}$ \\
\hline $\begin{array}{l}\text { Model Think Pair } \\
\text { Share }\end{array}$ & 41 (baik) & 0.297 & 0.266 & 4.827 & 5.895 & 1.917 & 2.333 \\
\hline $\begin{array}{l}\text { Media Crossword } \\
\text { Puzzle }\end{array}$ & 41 (baik) & 0.210 & 0.271 & 5.120 & 6.510 & 1.856 & 2.410 \\
\hline $\begin{array}{l}\text { Model Think Pair } \\
\text { Share dan Media } \\
\text { Crossword Puzzle }\end{array}$ & 52 (baik) & 0.326 & 0.059 & 5.502 & 5.439 & 3.856 & 2.510 \\
\hline $\begin{array}{l}\text { Kelas Kontrol } \\
\text { (Model Ceramah) }\end{array}$ & 37 (cukup) & 0.067 & 0.787 & 0.331 & 4.468 & 0.575 & 0.578 \\
\hline
\end{tabular}

\section{SIMPULAN DAN REKOMENDASI}

Berdasarkan hasil penelitian dan analisis data maka diperoleh kesimpulan dalam penelitian ini sebagai berikut: pembelajaran menggunakan model think pair share dan media crossword puzzle untuk meningkatkan minat belajar matematika siswa sekolah dasar di Desa Ngembalrejo Bae Kudus mempunyai pengaruh yang signifikan dan termasuk kategori baik, serta minat belajar yang tinggi.

Rekomendasi bagi penelitian lebih lanjut diharapkan mampu menerapkan metode pembelajaran yang tepat agar tujuan pembelajaran dapat tercapai maksimal. Sebagaimana mengenai pengaruh Model Think Pair Share dan Media Crossword Puzzle apabila digunakan untuk meningkatkan minat siswa. Ketika Model Think 
Pair Share dan Media Crossword Puzzle diterapkan dengan baik dalam proses pembelajaran, guru mempersiapkan segala sesuatunya dengan matang dan bagus, serta guru mampu merealisasikan apa yang dibuat dan direncanakan dengan baik maka hasilnya akan maksimal sehingga berdampak pada minat belajar siswa yang tinggi

\section{DAFTAR PUSTAKA}

Agus, S. (2014). Cooperative Learning. Yogyakarta: Pustaka Pelajar.

Azwar, S. (2020). Metode Penelitian. Yogyakarta: Pustaka Pelajar.

Darmadi. (2017). Pengembangan Model Metode Pembelajaran dalam Dinamika Belajar Siswa. Yogyakarta : Deepublish.

Djamarah, S. B. (2002). Strategi Belajar Mengajar. Jakarta: Rineka Cipta.

Mahmud. (2011). Metode Penelitian Pendidikan. Bandung: CV PUstaka Setia.

Masrukhin. (2014). Statistik Diskriptif dan Inferensial. Kudus: Media Ilmu Press.

Miftahul, H. (2013). Model-Model Pengajaran dan Pembelajaran. Yogyakarta: Pustaka Pelajar.

Muhammad, F., dan Sulistyorini. (2012). Belajar \& Pembelajaran: Meningkatkan Mutu Pembelajaran Sesuai Standar Nasional. Yogyakarta: Teras.

Multiyaningsih, E. (2013). Metode Penelitian Terapan Bidang Pendidikan. Bandung: Alfabeta.

Silberman, M. L. (2002). Active Learning: 101 Metode Pembelajaran Aktif. Yogyakarta : Pustaka Madani.

Slamet. (2003). Belajar dan Faktor-faktor yang Mempengaruhinya. Jakarta: Rineka Cipta.

Srianis, K., dkk. (2014). Penerapan Metode Bermain Puzzle Geometri untuk Meningkatkan Perkembangan Kognitif Anak dalam Mengenal Bentuk.

Sri, S. (2003). Think Pair Share Effect of Understanding the Concept and Achievement, Jurnal Internasional from The Faculty of Teacher Training and Education Sebelas Maret University Indonesia.
Rukaesih, A. (2015). Metodologi Penelitian Pendidikan. Jakarta: PT Raja Grafindo Persada.

Sugiono. (2013). Statistika Untuk Penelitian, Bandung : Alfabeta.

Sugiyono. (2008). Metode penelitian Kuantitatif Kualitataif dan $R \& D$. Bandung: Alfabeta.

Trianto. (2011). Model-Model Pembelajaran Inovatif Berorientasi Konstruktivisme. Jakarta: Prestasi Pustaka.

Zubaidah, A., dan Risnawati. (2016). Psikologi Pembelajaran Matematika. Yogyakarta: Aswaja Pressindo.

Webster, M. (2013). Webster's Ninth New Collagiate Dictionary. Merriam Webster Inc.

Yaumi, M. (2016). Pendidikan Karakter Landasan, Pilar, dan Implementasi. Jakarta: Prenadamedia Group.

Zubaedi. (2012). Desain Pendidikan Karakter. Jakarta: Kencana Prenada Media Group. 